\title{
Synthesis, Characterization, and Thermal Properties of Alkyl-Functional Naphthoxazines
}

\author{
Tamer Uyar, ${ }^{1,2}$ Jale Hacaloglu, ${ }^{3}$ Hatsuo Ishida ${ }^{1}$ \\ ${ }^{1}$ Department of Macromolecular Science and Engineering, Case Western Reserve University, Cleveland, Ohio 44106 \\ ${ }^{2}$ UNAM-Institute of Materials Science \& Nanotechnology, Bilkent University, Ankara 06800, Turkey \\ ${ }^{3}$ Department of Chemistry, Middle East Technical University, Ankara 06531, Turkey \\ Correspondence to: T. Uyar (E-mail: tamer@unam.bilkent.edu.tr) or H. Ishida (E-mail: hxi3@case.edu)
}

ABSTRACT: A series of alkyl-functional naphthoxazine resins having various alkyl chain lengths from $\mathrm{C} 1$ to $\mathrm{C} 18$ are synthesized with a high yield and high purity by the reactions of 1,5-dihydroxynaphthalene, formaldehyde, and aliphatic amines. The proposed chemical structures of the naphthoxazines are confirmed by high-resolution mass spectrometry, ${ }^{1} \mathrm{H}$ nuclear magnetic resonance spectroscopy, Fourier transform infrared spectroscopy, and pyrolysis mass spectrometry studies. The alkyl-functional naphthoxazines have shown low polymerization temperature characteristics where polymerization of these monomers is achieved in the range of $150-170^{\circ} \mathrm{C}$ yielding cross-linked polynaphthoxazines. The low-temperature polymerization characteristics and the associated thermal degradation behaviors are studied. (c) 2012 Wiley Periodicals, Inc. J. Appl. Polym. Sci. 127: 3114-3123, 2013

KEYWORDS: naphthoxazine; polynaphthoxazine; benzoxazines; thermoset; polymerization

Received 12 August 2011; accepted 13 March 2012; published online 19 May 2012

DOI: 10.1002/app.37692

\section{INTRODUCTION}

Benzoxazines are a new class of phenolic resins which have been developed recently. ${ }^{1-8}$ The benzoxazine resins are formed from a phenolic derivative, formaldehyde, and a primary amine. Similar to benzoxazine resins, naphthoxazines can be synthesized when phenolic precursor is replaced by hydroxyl naphthalenes. Despite the large number of studies on polybenzoxazines, only very few reports can be found in the literature on polynaphthoxazines. Shen and Ishida reported the preparation of difunctional naphthoxazine resins in order to increase the thermal stability and char yield of the resulting thermosets, polynaphthoxazines. ${ }^{9}$ A continuing approach was reported by Agag by incorporating additional polymerizable group in the naphthoxazines; a series of allylamine-based naphthoxazines were synthesized to improve the thermal stability of polynaphthoxazines with extended network via the polymerization of allyl functionality. ${ }^{10}$ Additionally, an interesting route was taken by Yagci and his research group where they have synthesized naphthoxazine terminated polymers of poly(propylene oxide)s and poly(3-caprolactone) (PCL). ${ }^{11,12}$ Mass spectrometric studies of naphthoxazines have been reported where ring-chain tautomerism of naphthoxazines, ${ }^{13,14}$ electron ionization mass spectra of nontautomerism-forming naphthoxazines ${ }^{15}$ and thermal degra- dation of aromatic amine-based polynaphthoxazines ${ }^{16}$ were studied. A brief study on clay-based polynaphthoxazine was also reported where the decomposition temperature of the naphthoxazine increased by the addition of an organoclay, showing a possible route for overcoming the low temperature degradation of polynaphthoxazines. ${ }^{17}$

Unlike benzoxazines, naphthoxazines suffer from low-thermal stability and require autoclave since evaporation of the monomer cannot be avoided during polymerization. In a previous report by Shen and Ishida, among the four different aromatic amine-based difunctional naphthoxazines obtained, only one of them was successfully polymerized in an autoclave to give voidfree resin. ${ }^{9}$ Moreover, Agag has reported similar problems where the thermal degradation/evaporation of allyl-functional naphthoxazines below $200^{\circ} \mathrm{C}$ was observed during thermal treatment of the monomers. ${ }^{10}$ Our recent study on the pyrolysis mass spectrometry analysis of aromatic amine-based naphthoxazine monomer has also proven that the evaporation and degradation of the monomer take place during the polymerization process. ${ }^{16}$

Here, we have synthesized a series of naphthoxazine resins having various alkyl chain lengths. Our study showed that these alkyl-functional naphthoxazines have low curing temperature characteristics in the range of $150-170^{\circ} \mathrm{C}$. For the aromatic 


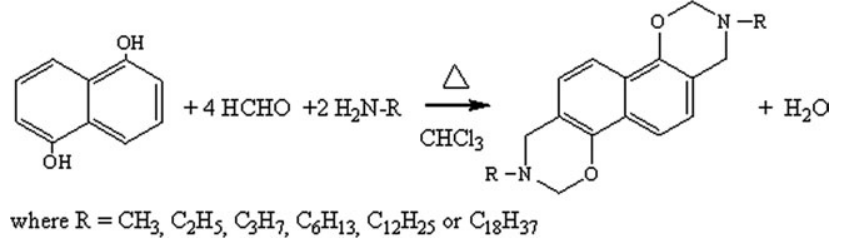

Scheme 1. Formation of alkyl-functional naphthoxazines.

amine-based naphthoxazines, the polymerization temperature was reported to be in the range of $220-290^{\circ} \mathrm{C}$ which is quite high compared with these alkyl-functional naphthoxazine resins. ${ }^{9,10,18}$ This dramatic structural effect on the lowering of polymerization temperature without added initiators or catalysts is similar to the recently reported results on benzoxazine monomers and main-chain type polybenzoxazines. ${ }^{19-22}$

\section{EXPERIMENTAL}

\section{Materials}

Dodecylamine (=99\%), hexylamine (99\%), propylamine (=99\%), ethylamine (70 wt \% in water), methylamine (40 wt \% in water), formaldehyde (37 wt \% in water), paraformaldehyde (95\%), 1,5-dihydroxynaphthalene (97\%), chloroform (99.8\%), methanol (99\%), and tetrahydrofuran were purchased from Sigma-Aldrich and octadecylamine $(=99.0 \%)$ was purchased from Fluka Chemical Companies. All chemicals were used without further purification.

\section{Naphthoxazine Monomer Synthesis}

The naphthoxazine monomers were prepared by mixing 0.02 mol of paraformaldehyde and 0.005 mol of 1,5 dihydroxynaphthalene in chloroform and adding $0.01 \mathrm{~mol}$ of selected amine reagent into the mixture. In case of methylamine, tetrahydrofuran was used as the solvent. The total weight of the reactants was about $10 \% \mathrm{w} / \mathrm{v}$ of the solvent in all cases. The homogeneous solution was refluxed for $5 \mathrm{~h}$, cooled to room temperature, and then the solvent was removed by rotary evaporator. The resulting product was washed with methanol several times for purification. The yield of the naphthoxazine monomers were $=85 \%$ for all cases. The synthetic route of naphthoxazine monomers and their physical/thermal properties are given in Scheme 1 and Table I, respectively.

\section{Polymerization of Naphthoxazine Monomers}

The polymerization profiles of naphthoxazine monomers are summarized in Table II. Monomer powders in an aluminum pan were placed in a conventional oven and heated for a total of $2 \mathrm{~h} ; 1 \mathrm{~h}$ at $150^{\circ} \mathrm{C}$ and $1 \mathrm{~h}$ at $170^{\circ} \mathrm{C}$ in air. Under the experimental conditions, evaporation of 1,5-DHN-cla and 1,5-DHNc2a were significant. Thus, to minimize the evaporation of these monomers, the samples were heated for $2 \mathrm{~h}$ at $210^{\circ} \mathrm{C}$ for $\mathbf{1 , 5}$ DHN-c1a, and $170^{\circ} \mathrm{C}$ for $1,5-D H N-c 2 a$ in a high-pressure DSC 2910 (TA Instruments) under a pressure of $2.75 \mathrm{MPa}$ obtained by nitrogen purge. Dark green or brown crosslinked materials, polynaphthoxazines were obtained for all cases after the polymerization processes.

\section{Characterization}

Proton nuclear magnetic resonance $\left({ }^{1} \mathrm{H}-\mathrm{NMR}\right)$ spectra (average of 128 transients) were taken on a Varian Inova NMR spectrometer at a proton frequency of $600 \mathrm{MHz}$. Deuterated chloroform was used as a solvent and tetramethylsilane was added as an internal standard.

High resolution mass spectra studies were performed by Agilent 6210 Accurate-Mass Time-of-Flight mass spectrometer.

Fourier transform infrared (FTIR) spectra (coadded scans of 16) of naphthoxazine monomers and cross-linked polynaphthoxazines, as $\mathrm{KBr}$ pellets, were obtained on a Bomem Michelson $\mathrm{MB}$ 100 , with a resolution $2 \mathrm{~cm}^{-1}$ under dry air purge using a deuterated triglycine sulfate detector (DTGS). Additionally, to investigate the structural changes occurring during the polymerization of the naphthoxazine monomers, nonisothermal FTIR studies were performed. The monomers, which were cast from chloroform solution on a $\mathrm{KBr}$ disc and placed in a temperaturecontrolled hot cell (Connecticut Instruments), were heated at a rate of $\sim 30^{\circ} \mathrm{C} / \mathrm{min}$ in the temperature range of $100-250^{\circ} \mathrm{C}$. The FTIR spectrum was recorded while keeping the sample at a target temperature for about $2 \mathrm{~min}$.

Differential scanning calorimetry (DSC) experiments were conducted to study the polymerization behavior of the naphthoxazines on a TA Instruments DSC 2920. The temperature scanning was nonisothermal and the temperature sweep was from room temperature to $275^{\circ} \mathrm{C}$ at a heating rate of $10^{\circ} \mathrm{C} / \mathrm{min}$ under nitrogen purge $(60 \mathrm{~mL} / \mathrm{min})$.

Thermogravimetric analyses (TGA) were performed on a TA Instruments TGA 2950 under nitrogen atmosphere at a flow rate of $90 \mathrm{~mL} / \mathrm{min}$ and a heating rate of $20^{\circ} \mathrm{C} / \mathrm{min}$.

Quadruple mass spectrometry system (HP model 5973) coupled with a JHP SIS direct insertion probe was used for direct pyrolysis experiments. Samples $(0.01 \mathrm{mg})$ were pyrolyzed in flared glass sample vials. $70 \mathrm{eV}$ EI mass spectra were recorded at a scan rate of 2 scans/s during the pyrolysis. The temperature was increased from room temperature at a heating rate of $20^{\circ} \mathrm{C} / \mathrm{min}$ to the maximum attainable temperature of $450^{\circ} \mathrm{C}$. All pyrolysis experiments were repeated at least twice to confirm reproducibility.

\section{RESULTS AND DISCUSSION}

\section{Structural Characterization of Naphthoxazine Monomers}

The alkyl-functional naphthoxazines having different alkyl chain length from $\mathrm{C} 1$ to $\mathrm{C} 18$ were obtained by the reaction of 1,5dihydroxynaphthalene with formaldehyde and series of amines (methylamine, ethylamine, propylamine, hexylamine, dodecylamine, and octadecylamine) as shown in Scheme 1. The chemical structures and the physical properties of the synthesized naphthoxazines are summarized in Table I. The proposed chemical structures of the alkyl-functional naphthoxazines were confirmed by high resolution mass spectrometry (HR-MS) and ${ }^{1} \mathrm{H}-$ NMR studies.

The HR-MS results for the synthesized naphthoxazines are as follows: 1,5-DHN-cla $(\mathrm{M}+\mathrm{H})^{+}$calculated: 271.1441; observed: 271.1437. 1,5-DHN-c2a $\quad(\mathrm{M}+\mathrm{H})^{+} \quad$ calculated: 299.1754; 
Table I. Chemical Structure and Physical Properties of Alkyl-Functional Naphthoxazine Monomer
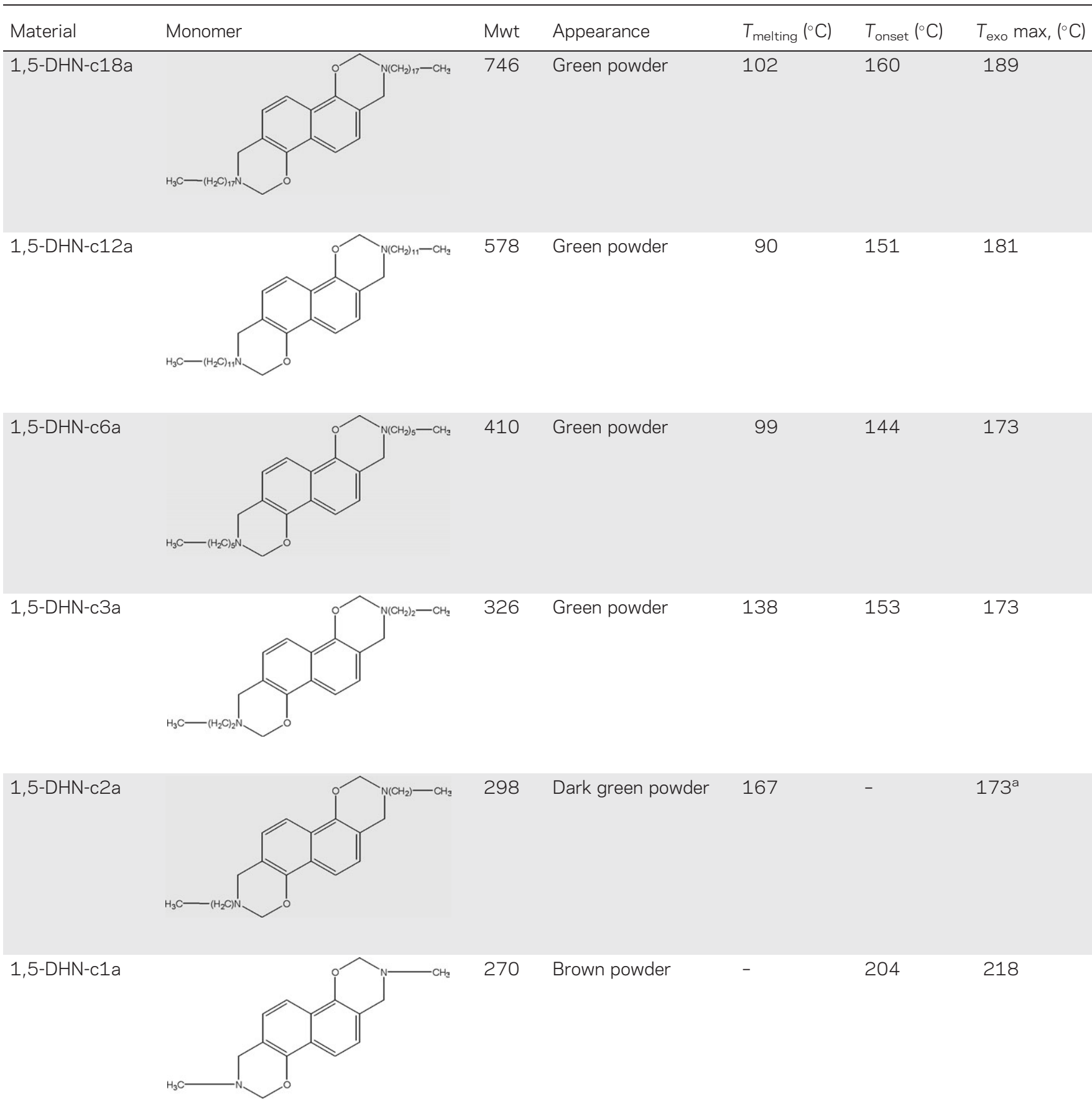

${ }^{a}$ Due to the heavily overlapped melting endotherm peak, the exact exotherm peak position could not be determined. The true peak position is expected to be below $173^{\circ} \mathrm{C}$

observed: 299.1734. 1,5-DHN-c3a $\quad(\mathrm{M}+\mathrm{H})^{+}$calculated: 327.2067; observed: 327.2061. 1,5-DHN-c6a $(\mathrm{M}+\mathrm{H})^{+}$calculated: 411.3006; observed: 411.3007. 1,5-DHN-c12a $(\mathrm{M}+\mathrm{H})^{+}$ calculated: 578.4811; observed: 578.4808. 1,5-DHN-c18a $(\mathrm{M}+\mathrm{H})^{+}$calculated: 747.6762; observed: 747.6756.

All the alkyl-functional naphthoxazine monomers showed typical two singlet resonances at $\sim 4.1$ and $\sim 5.0 \mathrm{ppm}$ in their ${ }^{1} \mathrm{H}$ -
NMR spectra (Figure 1) due to the methylene units of oxazine ring; $-\mathrm{Ar}-\mathrm{CH}_{2}-\mathrm{N}$ and $-\mathrm{O}-\mathrm{CH}_{2}-\mathrm{N}$, respectively. ${ }^{1}$ The aromatic protons of naphthoxazines give rise to multiplet in the range 7.0-7.6 ppm. The resonances recorded in the range of 0.9-1.6 ppm are associated with the aliphatic protons of the alkyl chains and the resonance recorded at around $2.8 \mathrm{ppm}$ is assigned to the protons of methylene units next to the nitrogen 
Table II. Polymerization Conditions and Thermal Degradation Behavior of Polynaphthoxazines

\begin{tabular}{|c|c|c|c|c|}
\hline Material & $\begin{array}{l}\text { Polymerization } \\
\text { temperature }\end{array}$ & $T_{d 5}{ }^{a}$ & $T_{\mathrm{d} 10}{ }^{b}$ & $\begin{array}{l}\text { Char } \\
\text { yield } \\
(\%)\end{array}$ \\
\hline Poly-1,5-DHN-c18a & $\begin{array}{l}150^{\circ} \mathrm{C} \\
(1 \mathrm{~h})+170^{\circ} \mathrm{C}(1 \mathrm{~h})\end{array}$ & 188 & 212 & 19 \\
\hline Poly-1,5-DHN-c12a & $\begin{array}{l}150^{\circ} \mathrm{C} \\
(1 \mathrm{~h})+170^{\circ} \mathrm{C}(1 \mathrm{~h})\end{array}$ & 216 & 248 & 29 \\
\hline Poly-1,5-DHN-c6a & $\begin{array}{l}150^{\circ} \mathrm{C} \\
(1 \mathrm{~h})+170^{\circ} \mathrm{C}(1 \mathrm{~h})\end{array}$ & 223 & 248 & 36 \\
\hline Poly-1,5-DHN-c3a & $\begin{array}{l}150^{\circ} \mathrm{C} \\
(1 \mathrm{~h})+170^{\circ} \mathrm{C}(1 \mathrm{~h})\end{array}$ & 224 & 250 & 46 \\
\hline Poly-1,5-DHN-c2a & $170^{\circ} \mathrm{C}(2 \mathrm{~h})$ & 249 & 278 & 47 \\
\hline Poly-1,5-DHN-c1a & $210^{\circ} \mathrm{C}(2 \mathrm{~h})$ & 325 & 424 & 66 \\
\hline
\end{tabular}

aThe temperature at which 5\% weight loss observed in TGA thermograms under nitrogen atmosphere, ${ }^{\mathrm{b}}$ The temperature at which $10 \%$ weight loss observed in TGA thermograms under nitrogen atmosphere, ${ }^{\circ}$ The residual weight at $800^{\circ} \mathrm{C}$ under nitrogen atmosphere.

$\left(-\mathrm{N}-\mathrm{CH}_{2}-\mathrm{C}\right)$. In short, the NMR data confirms the proposed structure of the alkyl-functional naphthoxazine monomers. The lack of any resonance around $3.7 \mathrm{ppm}$, typical frequency for ring opened oligomers due to the Mannich bridge protons of open oxazine rings ${ }^{1} ;-\mathrm{CH}_{2}-\mathrm{NPh}-\mathrm{CH}_{2}-$ structure, indicates that all the monomers are free of ring-opened oligomers, and the purification (washing with methanol) was good enough to obtain samples with high purity. Moreover, integration analysis of the oxazine and aromatic proton peaks pointed out that the closed-ring structured monomer is at least 99\%. It is important to have high purity monomers, free of phenolic impurities, and ring-opened oligomeric species especially for the evaluation of the rate of polymerization since these species act as cationic initiators and lower the polymerization temperature of the monomers. The polymerization temperatures observed in this study for alkyl-functional naphthoxazines were quite low compared

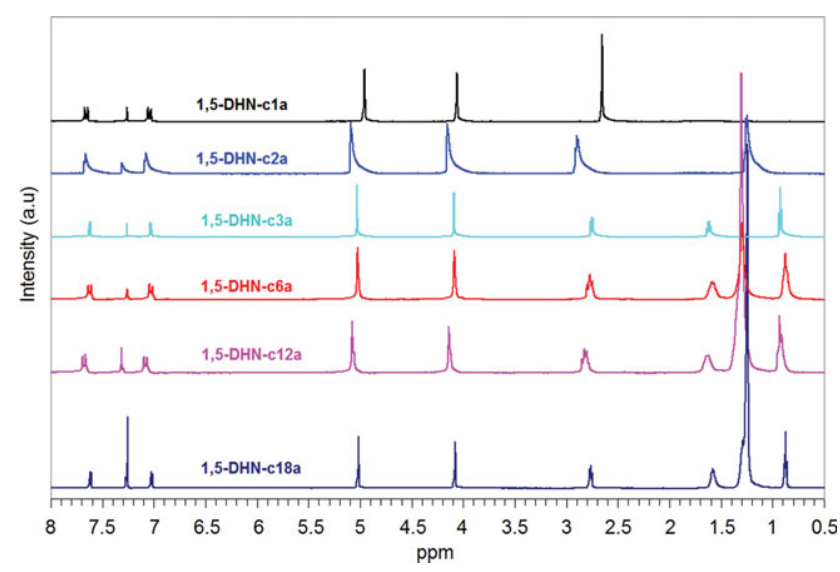

Figure 1. ${ }^{1} \mathrm{H}-\mathrm{NMR}$ spectra of alkyl-functional naphthoxazine monomers. [Color figure can be viewed in the online issue, which is available at wileyonlinelibrary.com.]

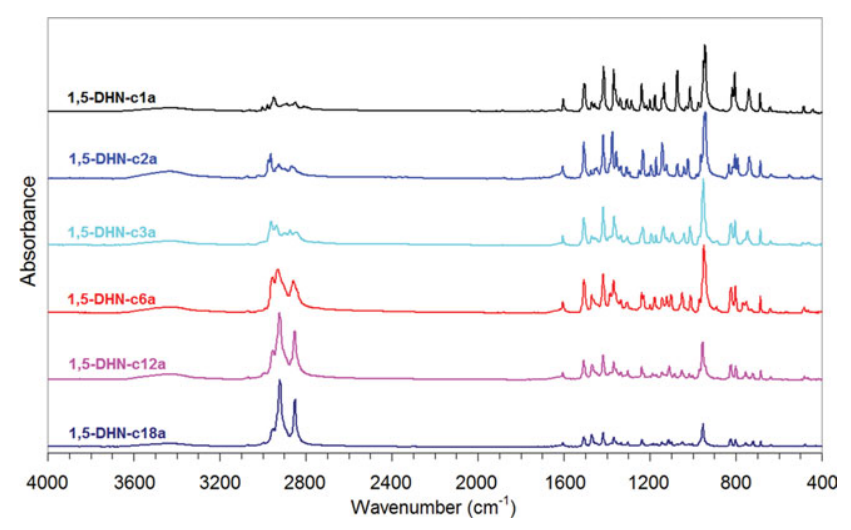

Figure 2. FTIR spectra of alkyl-functional naphthoxazine monomers. [Color figure can be viewed in the online issue, which is available at wileyonlinelibrary.com.]

with those of the ordinary benzoxazines and aromatic aminebased naphthoxazines. ${ }^{1-10}$ Since, the NMR and MS data showed high purity monomers free of oligomers, the low polymerization temperatures of these monomers can directly be attributed to monomer characteristics. The polymerization behaviors of these monomers are discussed in detail in the following sections.

Figure 2 shows the FTIR spectra of the alkyl-functional naphthoxazine monomers. As shown in Figure 2, the presence of characteristic band at $952-942 \mathrm{~cm}^{-1}$ due to the $\mathrm{C}-\mathrm{H}$ out-ofplane deformation mode of the $\alpha \beta$-disubstituted naphthalene ring indicated the formation of oxazine ring for all monomers. ${ }^{9}$ Additional bands observed at $1237-1232 \mathrm{~cm}^{-1}$ (the asymmetric stretching mode of $\mathrm{Ar}-\mathrm{O}-\mathrm{C}$ ), $1048-1040 \mathrm{~cm}^{-1}$ (the symmetric stretching mode of $\mathrm{C}-\mathrm{O}-\mathrm{C}$ ), $1337-1334 \mathrm{~cm}^{-1}$ (the $\mathrm{CH}_{2}$ wagging mode of oxazine ring) and $3072-3068 \mathrm{~cm}^{-1}$ (the stretching modes of aromatic $\mathrm{C}-\mathrm{H}$ ) confirmed the proposed structure of the naphthoxazine monomers. The intensity of the peaks at 2950-2860 $\mathrm{cm}^{-1}$ (the stretching modes of aliphatic $\mathrm{C}-\mathrm{H}$ ) increased as the alkyl chain length increased from $\mathrm{C} 1$ to $\mathrm{C} 18$.

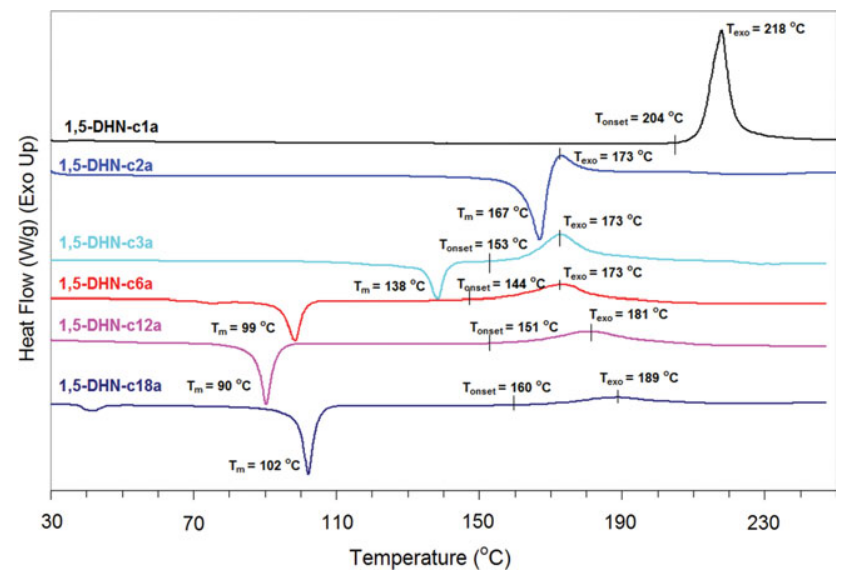

Figure 3. DSC thermograms of alkyl-functional naphthoxazine monomers. [Color figure can be viewed in the online issue, which is available at wileyonlinelibrary.com.] 

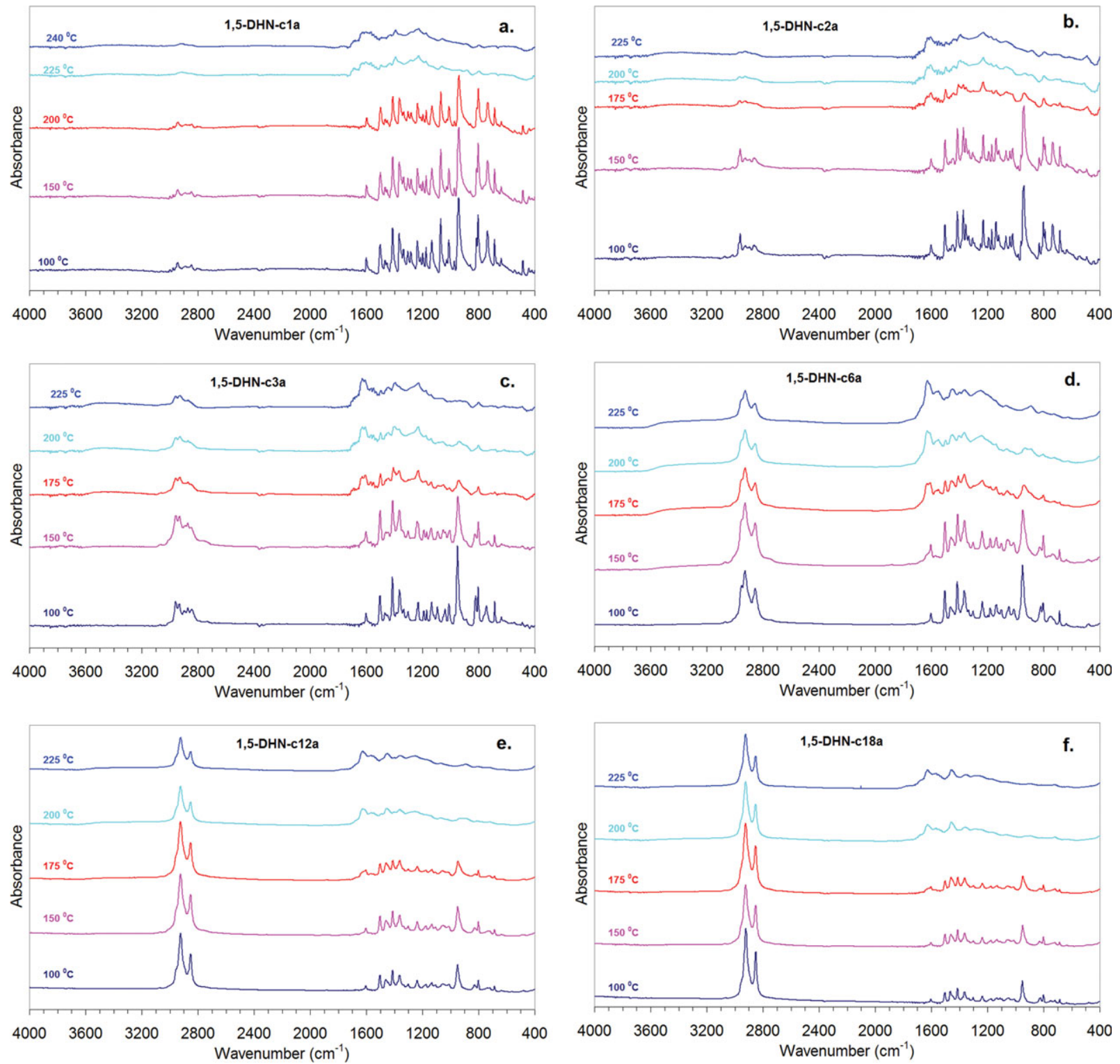

Figure 4. FTIR spectra of alkyl-functional naphthoxazine monomers at different temperatures. (a) 1,5-DHN-cla, (b) 1,5-DHN-c2a, (c) 1,5-DHN-c3a, (d) 1,5-DHN-c6a, (e) 1,5-DHN-c12a, (f) 1,5-DHN-c18a. (Note: the heating is nonisothermal). [Color figure can be viewed in the online issue, which is available at wileyonlinelibrary.com.]

Polymerization Behavior of Naphthoxazines

The polymerization behavior of the alkyl-functional naphthoxazine monomers was studied by differential scanning calorimetry (DSC). The nonisothermal DSC thermograms for each monomer are given in Figure 3. The thermal properties, including melting points and exotherms (onset and peak maximum) corresponding to the ring-opening polymerization of the monomers, are summarized in Table I. The melting point $\left(T_{m}\right)$ for the monomers was in the range of $90-167^{\circ} \mathrm{C}$ and the $T_{m}$ was increased as the length of the alkyl chain decreased from $\mathrm{C} 12$ to C2. In case of 1,5-DHN-cla monomer, no $T_{m}$ was detected but only an exotherm peak with maximum at $218^{\circ} \mathrm{C}$ was recorded. The onset and peak maxima of the exotherms for the other monomers were in the range of $144-160^{\circ} \mathrm{C}$ and $173-189^{\circ} \mathrm{C}$, respectively. As the alkyl chain length decreased from C18 to C2 in the monomers, it was observed that the onset and peak maxima of the exotherms were reduced to lower temperatures. It was also noted that the melting point and the exotherm temperature approached closer as the length of the alkyl chain decreased in monomers.

The polymerization of the alkyl-functional naphthoxazine monomers were carried out according to the exotherm temperatures obtained from DSC studies. The polymerization temperature profiles are given in Table II. The samples 1,5-DHN-c18a, 1,5-DHN-c12a, 1,5-DHN-c6a, and 1,5-DHN-c3a were polymerized step-wise at $150^{\circ} \mathrm{C}$ for $1 \mathrm{~h}$ and $170^{\circ} \mathrm{C}$ for an additional $1 \mathrm{~h}$ in a conventional temperature controlled oven in air. In case of 

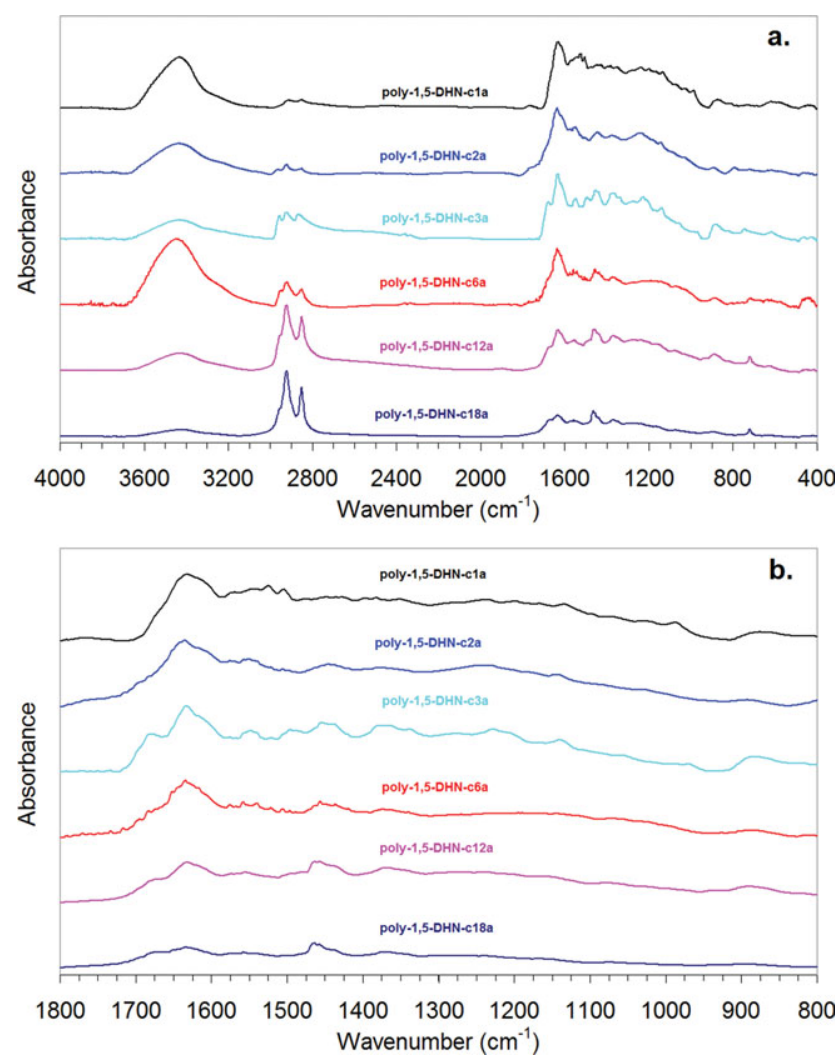

Figure 5. FTIR spectra of (a) polynaphthoxazines, (b) the zooming of the region between 1800 and $-800 \mathrm{~cm}^{-1}$. [Color figure can be viewed in the online issue, which is available at wileyonlinelibrary.com.]

1,5-DHN-c2a and 1,5-DHN-c1a, the polymerization was performed under pressure in the DSC heating cell using nitrogen purge for $2 \mathrm{~h}$ at 170 and $210^{\circ} \mathrm{C}$, respectively. Overall, except for 1,5-DHN-cla monomer, the exothermic peak maximum recorded for the alkyl-functional naphthoxazine monomers were in the range of $173-189^{\circ} \mathrm{C}$. This temperature range is extremely low compared with the typical exothermic peak maximum range (around $210-240^{\circ} \mathrm{C}$ ) of benzoxazines and aromatic amine-based naphthoxazines. ${ }^{1-10}$ As discussed previously, the monomers were free of raw materials and oligomeric species. Thus, the low polymerization temperature of these monomers is an inherent characteristic indicating the potential use in the development of polymer-polymer composite materials.

Nonisothermal FTIR studies have also been carried out to investigate the structural changes occurring during the polymerization processes (Figure 4). Except for 1,5-DHN-cla, the characteristic absorption band at $942-952 \mathrm{~cm}^{-1}$ attributed to the benzene ring mode of naphthoxazine gradually decreased as the polymerization proceeded, and disappeared at $200^{\circ} \mathrm{C}$ for all the naphthoxazine monomers. For 1,5-DHN-cla, this mode at 942 $\mathrm{cm}^{-1}$ disappeared at $225^{\circ} \mathrm{C}$ indicating that the ring opening reaction had completed at higher temperatures compared with the rest of the monomers in accordance with the DSC data where a higher exotherm temperature $\left(218^{\circ} \mathrm{C}\right)$ was observed for
1,5-DHN-cla. These results further confirm that the alkyl-functional naphthoxazine monomers have low polymerization temperature.

Figure 5 shows the FTIR spectra of the crosslinked polynaphthoxazines. The absorption peaks around $952-942 \mathrm{~cm}^{-1}, 1048-$ $1040 \mathrm{~cm}^{-1}, 1237-1232 \mathrm{~cm}^{-1}$, and $1337-1334 \mathrm{~cm}^{-1}$, associated with naphthoxazine ring structure disappeared totally, indicating that the applied polymerization conditions (Table II) were successful for the complete ring opening of the oxazine groups in the monomers yielding crosslinked materials. The peaks observed at $2950-2860 \mathrm{~cm}^{-1}$ (the stretching mode of aliphatic $\mathrm{C}-\mathrm{H}$ ) for all the polynaphthoxazines elucidated that the alkyl chains present in the monomers are still intact with the material after crosslinking reaction.

It is worth mentioning that evaporation was observed during polymerization of 1,5-DHN-cla and 1,5-DHN-c2a in open air. It was not possible to polymerize the samples without applying pressure, and, therefore, a high-pressure DSC cell was used to minimize the evaporation of these monomers. Naphthoxazine monomers, both aromatic amine and allylamine based, are commonly reported to suffer from evaporation during polymerization. ${ }^{9,10,16}$ Yet, polymerization and subsequent cross-linking
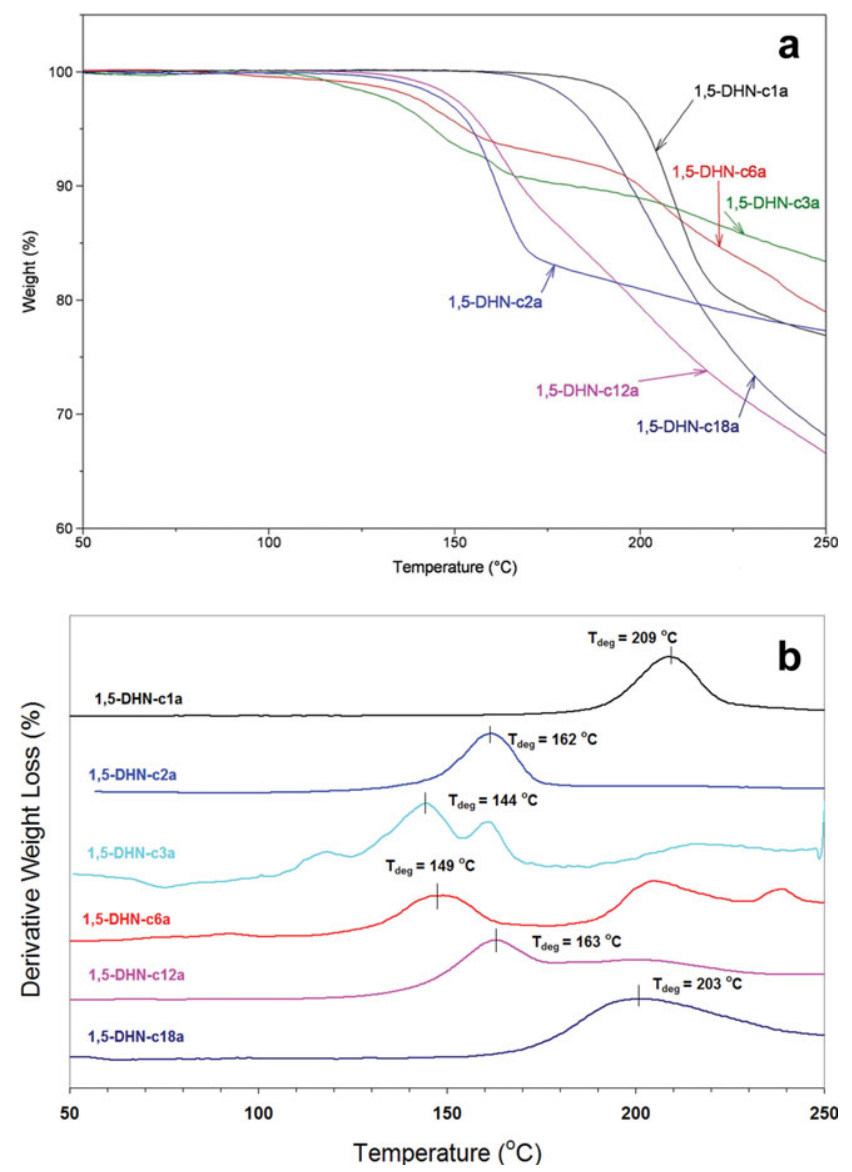

Figure 6. TGA of alkyl-functional naphthoxazines: (a) weight loss (\%) and (b) derivative weight loss (\%). [Color figure can be viewed in the online issue, which is available at wileyonlinelibrary.com.] 

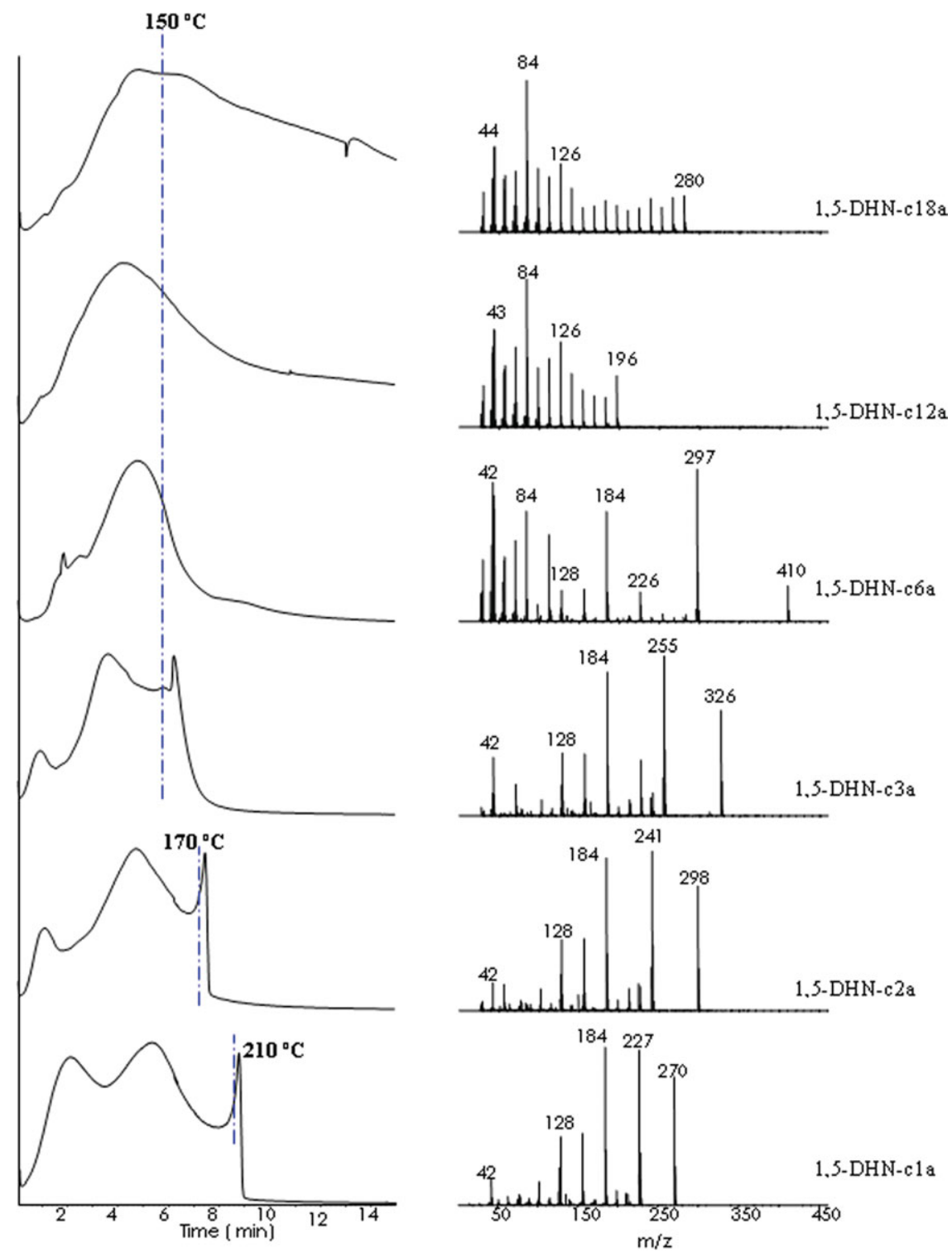

Figure 7. The TIC curves and pyrolysis mass spectra of naphthoxazine monomers recorded at peak maximum present in the TIC curves. [Color figure can be viewed in the online issue, which is available at wileyonlinelibrary.com.]

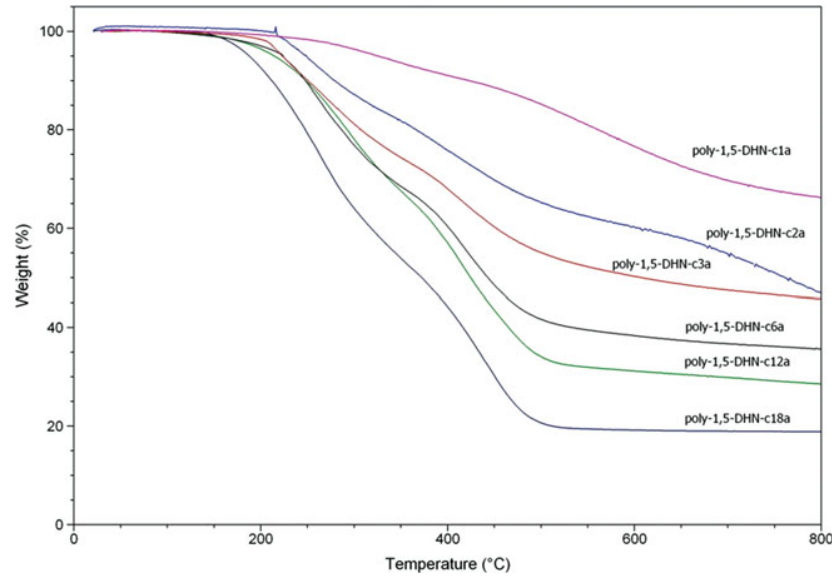

Figure 8. TGA thermograms of polynaphthoxazines. [Color figure can be viewed in the online issue, which is available at wileyonlinelibrary.com.]

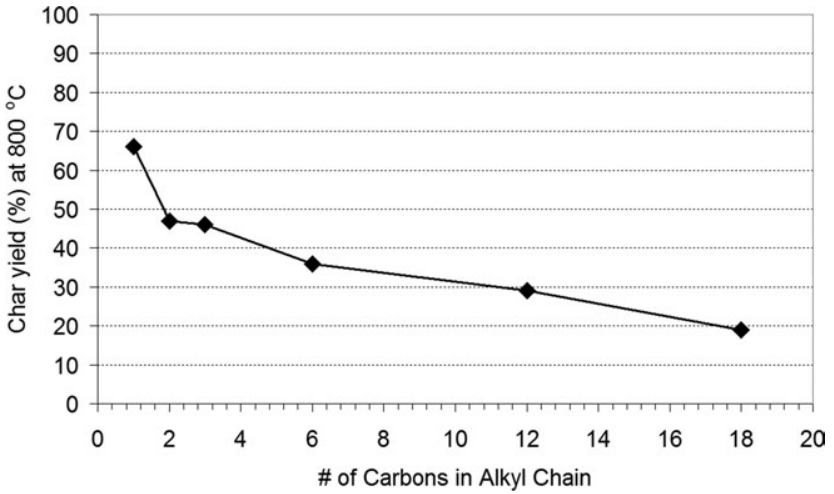

Figure 9. The char yield at $800^{\circ} \mathrm{C}$ for polynaphthoxazines with respect to number of carbon in alkyl chain of naphthoxazine monomers. (The data was obtained by TGA under nitrogen atmosphere). 
I.TIC curves
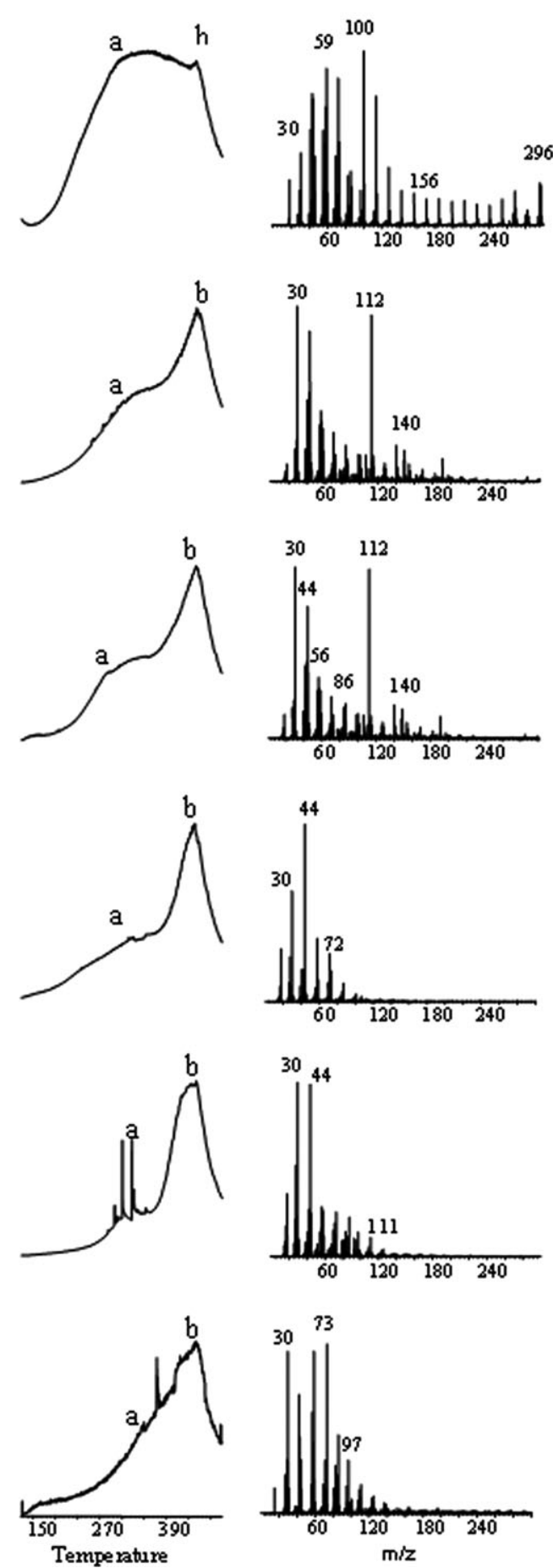

III. mass spectra at $b$
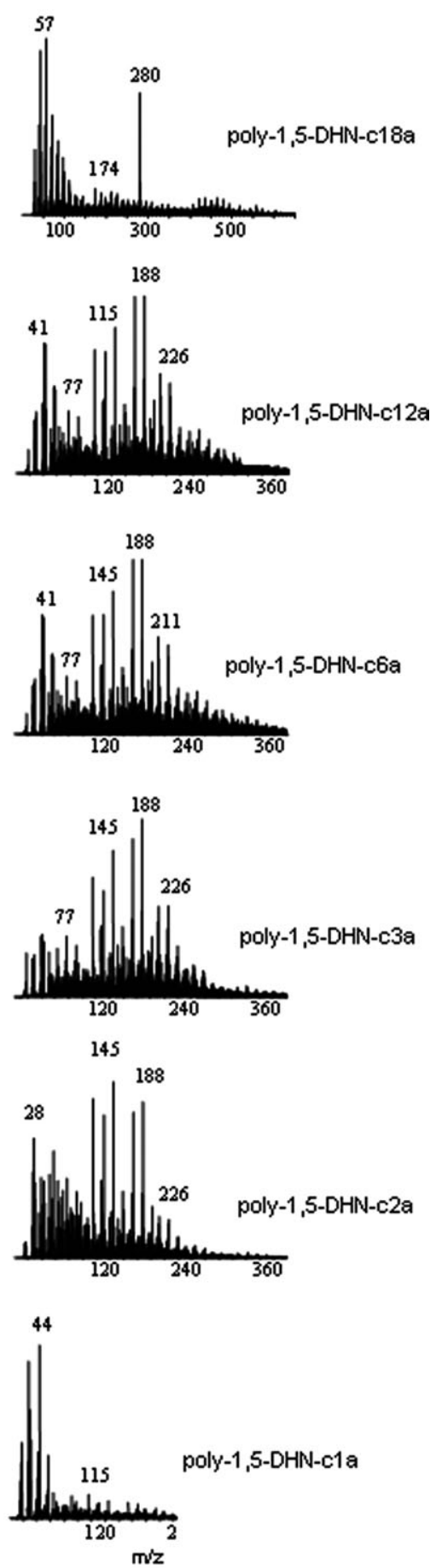

Figure 10. The TIC curves and pyrolysis mass spectra of polynaphthoxazines.

was possible for these monomers in open air and polynaphthoxazines were obtained.

To have better understanding for the thermal behavior of the naphthoxazine monomers, TGA and pyrolysis mass spectrometry (MS) analyses for these materials were performed. Figure 6 shows the TGA thermograms and derivative weight losses of the naphthoxazine monomers. The degradation peak maximum $\left(T_{\text {deg }}\right)$ was highest for 1,5-DHN-cla monomer which was observed at around $210^{\circ} \mathrm{C}$ elucidating that this monomer has the highest thermal stability. When the $T_{\mathrm{deg}}$ values of the monomers were compared, there was no consistent correlation found in terms of alkyl chain length, yet, the $T_{\text {deg }}$ was decreased from 


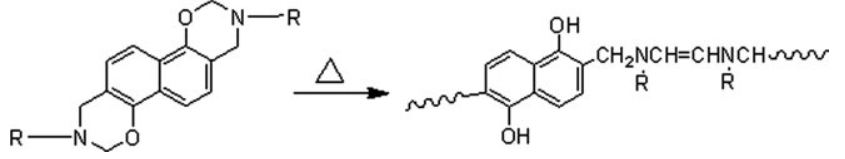

Scheme 2. Proposed polymerization mechanism for naphthoxazines.

C18 to C3 which was recorded at around 203, 163, 149, and $144^{\circ} \mathrm{C}$ for 1,5-DHN-c18a, 1,5-DHN-c12a, 1,5-DHN-c6a, 1,5DHN-c3a, respectively. The monomers having longer alkyl chains (1,5-DHN-c18a and 1,5-DHN-c12a) have shown higher $T_{\text {deg }}$ values compared with 1,5-DHN-c6a and 1,5-DHN-c3a and this is possibly because they were not subjected to evaporation as observed by pyrolysis MS studies which was discussed in the following section. In brief, TGA showed weight losses in the range of $145-210^{\circ} \mathrm{C}$ for the naphthoxazine monomers which was close to the exotherm temperatures detected in DSC studies indicating that these monomers were subjected to both evaporation/degradation and polymerization at these temperature ranges.

Pyrolysis MS studies for the monomers under the same heating conditions were also carried out and evolution of monomers were continuously detected during the heating processes up to the polymerization temperatures given in Table II. In Figure 7, the total ion current (TIC) (variation of total ion yield as a function of temperature) curves and the pyrolysis mass spectra recorded at the peak maximum of the TIC curve of the monomers are shown. The TIC curves of all the samples under investigation showed more than one peak. Yet, for all the naphthoxazine monomers, the pyrolysis mass spectra were almost identical up to the polymerization temperature. Except for 1,5-DHNc12a and 1,5-DHN-c18a, molecular ion peaks at $\mathrm{m} / \mathrm{z}=270$, 298, 326, and 410 for 1,5-DHN-c1a, 1,5-DHN-c2a, 1,5-DHNc3a, and 1,5-DHN-c6a were detected at 270, 298, 326, and 410 $\mathrm{Da}$, respectively. The relative intensity of the molecular ion peak decreased as the chain length of the alkyl substituent increased. For 1,5-DHN-c12a and 1,5-DHN-c18a, the molecular ion peak was undetectable as expected for molecules involving long alkyl chains (Figure 7). For all the monomers, the fragmentation pattern was in accordance with the proposed structures confirmed by HR-MS and ${ }^{1} \mathrm{H}-\mathrm{NMR}$, pointing out evaporation of the monomers before any decomposition. However, above the polymerization temperature, the relative yields of low mass fragment ions which are attributed to the alkyl amines increased, indicating the cleavage of side chains. Thus, it can be concluded that alkyl amines were eliminated at least to a certain extent at temperatures around the polymerization temperature. For all the alkyl-substituted naphthoxazines, except for 1,5-DHN-cla, elimination of aminomethyl radical, $\mathrm{CH}_{2}=\mathrm{NH}_{2}$ was continued in this region where almost no evolution of other product was detected. Hence, it can further be concluded that polymerization of naphthoxazines just above this temperature yielded a structure that can readily lose $\mathrm{CH}_{2}=\mathrm{NH}_{2}$ by some rearrangement reactions.

\section{Thermal Behavior of Polynaphthoxazines}

The thermal stability of alkyl-functional polynaphthoxazines were studied by TGA (Figure 8) and the findings including decomposition temperatures and char yields are listed in Table II and Figure 9. The decomposition of the polynaphthoxazines started around $200^{\circ} \mathrm{C}$ for the samples containing longer alkyl chains. As the length of the alkyl chains increased, the thermal degradation was shifted to lower temperatures and a decrease in the char yield was detected (Figure 9). This behavior was expected since alkyl groups degrade and form gaseous species. Poly-1,5-DHN-cla showed remarkably high char yield (66\%) compared with phenolic resins and other polybenzoxazines and may have a potential use in the development of carbon-carbon composites for high temperature applications.

The TIC curves for polynaphthoxazines showed two broad overlapping peaks indicating a complex decomposition mechanism (Figure 10). The pyrolysis mass spectra for polynaphthoxazines, poly-1,5-DHN-c1a to poly-1,5-DHN-c18a recorded in the temperature range $150-190^{\circ} \mathrm{C}$ were dominated by peaks due to the characteristic alkyl amine fragments such as aminomethyl radical $\mathrm{CH}_{2}=\mathrm{NH}_{2}(\mathrm{~m} / \mathrm{z}=30 \mathrm{Da}), \mathrm{CH}_{3} \mathrm{CH}_{2} \mathrm{NH}$ or $\mathrm{C}_{2} \mathrm{H}_{6} \mathrm{~N}(\mathrm{~m} / \mathrm{z}=$ $44 \mathrm{Da}), \mathrm{C}_{3} \mathrm{H}_{7} \mathrm{~N},(\mathrm{~m} / \mathrm{z}=57 \mathrm{Da}), \mathrm{C}_{4} \mathrm{H}_{10} \mathrm{~N},(\mathrm{~m} / \mathrm{z}=72 \mathrm{Da})$ and $\mathrm{C}_{6} \mathrm{H}_{11} \mathrm{~N}(\mathrm{~m} / \mathrm{z}=97 \mathrm{Da})$. It should be noted that even for poly1,5-DHN-cla, peaks indicating loss of alkyl chains or alkyl amines involving more than $3 \mathrm{C}$ atoms were detected. The presence of these peaks with significantly high $\mathrm{m} / \mathrm{z}$ values compared with those of the related $\mathrm{CH}_{2} \mathrm{~N}(\mathrm{R}) \mathrm{CH}_{2}$ groups (i.e., detection of $\mathrm{C}_{6} \mathrm{H}_{11} \mathrm{~N}$ peak at $97 \mathrm{Da}$ ) indicated the coupling of alkyl amine radicals generated by the ring opening of side chains of alkyl functionalized naphthoxazine monomers during the polymerization process as shown in Scheme 2. As the alkyl chain length increased, relative intensity of the peaks due to the high mass amines also increased. In fact, the bifunctional naphthoxazine monomers do not have a free ortho position as in the case of monofunctional benzoxazines. On the other hand, both of the para positions should be deactivated due to the presence of the other $\mathrm{OH}$ group. Thus, polymerization by the attack of $-\mathrm{NCH}_{2}$ directly to the naphthoxazine ring may be thought to be less likely compared with benzoxazines. Thus, the proposed mechanism presented in Scheme 2 is in accordance with general expectations and should be one of the major polymerization pathways.

Except for poly-1,5-DHN-c1a, intense peaks that can readily be attributed to fragments involving naphthoxazine ring, such as peaks at 174 and 188 Da due to $\mathrm{C}_{10} \mathrm{H}_{5}(\mathrm{OH})_{2} \mathrm{CH}_{2}$ and $\mathrm{C}_{10} \mathrm{H}_{4}(\mathrm{OH})_{2} \mathrm{CH}_{2} \mathrm{NH}_{2}$, were detected at temperatures above $400^{\circ} \mathrm{C}$, pointing out degradation of the polymer. In case of poly-1,5-DHN-cla, the char yield is expectedly the highest as the relative weight contribution of the amine components that is easier to evaporate to the naphthalene component is the lowest. For all polynaphthoxazines, except for poly-1,5-DHN-cla, the peak at $280 \mathrm{Da}$ may be attributed to two naphthoxazine rings connected by acetylene unit that can be generated upon loss of alkyl amine linkages. It may be concluded that polymerization of alkyl amine-functionalized naphthoxazines proceeded through the coupling of alkyl amine radicals and degradation of these polynaphthoxazines started by cleavage of these weak linkages. It may further be concluded that, formation of crosslinked 
structures by coupling of the radicals generated by loss of alkyl amines is more likely in case of poly-1,5-DHN-cla.

In brief, the pyrolysis MS data indicated strong evidences for a polymerization mechanism involving coupling of alkyl amine generated by ring opening of side chains were detected. The increase in alkyl chain length not only caused a decrease in thermal stability of the polymer but also inhibited crosslinking reactions and decreased the char yield. The details of pyrolysis studies and the degradation mechanism of these polynaphthoxazines will be the subject of future studies.

\section{CONCLUSIONS}

In this study, a series of naphthoxazine resins having alkyl chain lengths from $\mathrm{C} 1$ to $\mathrm{C} 18$ are synthesized. These alkyl-functional naphthoxazines have shown low polymerization temperature characteristics in the range of $150-170^{\circ} \mathrm{C}$, yielding cross-linked polynaphthoxazines. DSC, TGA, and pyrolysis MS data indicated that these alkyl-functional naphthoxazine monomers are subjected to evaporation, degradation, and polymerization at the same time during curing process. The low-temperature polymerization characteristics and the existence of the alky chain moiety in the structure could be useful to develop polymerpolymer composite materials from these alkyl-functional naphthoxazines resins. Yet, similar setback common to other naphthoxazine resins was also observed for these naphthoxazine monomers, that is, the evaporation and polymerization at the same time during curing at elevated temperature was recorded, indicating the difficulty of their polymerization process.

\section{ACKNOWLEDGEMENTS}

State Planning Organization of Turkey (DPT) is acknowledged for the support of UNAM-Institute of Materials Science and Nanotechnology at Bilkent University. The authors thank Z. Koyuncu for performing DP-MS experiments.

\section{REFERENCES}

1. Ishida, H.; Agag, T. Handbook of Benzoxazine Resins. Elsevier: Netherlands, 2011.
2. Ning, X.; Ishida, H. J. Polym. Sci. Part A: Polym. Chem. 1994, 32, 1121.

3. Ghosh, N. N.; Kiskan, B.; Yagci, Y. Prog. Polym. Sci. 2007, 32, 1344.

4. Yagci, Y.; Kiskan, B.; Ghosh, N. N. J. Polym. Sci. Part A: Polym. Chem. 2009, 47, 5565.

5. Ishida, H.; Low, H. Y. Macromolecules 1997, 30, 1099.

6. Ishida, H.; Ohba, S. Polymer 2005, 46, 5588.

7. Chaisuwan, T.; Ishida, H. J. Appl. Polym. Sci. 2010, 117, 2559.

8. Velez-Herrera, P.; Doyama, K.; Abe, H.; Ishida, H. Macromolecules 2008, 41, 9704.

9. Shen, S. B.; Ishida, H. J. Appl. Polym. Sci. 1996, 61, 1595.

10. Agag, T. J. Appl. Polym. Sci. 2006, 100, 3769.

11. Kiskan, B.; Yagci, Y. Polymer 2005, 46, 11690.

12. Yildirim, A.; Kiskan, B.; Demirel, A. L.; Yagci, Y. Eur. Polym. J. 2006, 42, 3006.

13. Szatmari, I.; Martinetk, T. A.; Lazar, L.; Fulop, F. Tetrahedron 2003, 59, 2877.

14. Szatmari, I.; Martinek, T. A.; Lazar, L.; Koch, A.; Kleinpeter, E.; Neuvonen, K.; Fulop, F. J. Org. Chem. 2004, 69, 3645.

15. Martiskainen, O.; Fulop, F.; Szatmari, I.; Pihlaja, K. ARKIVOC 2009, 3, 115.

16. Uyar, T.; Koyuncu, Z.; Ishida, H.; Hacaloglu, J. Polym. Degrad. Stab. 2008, 93, 2096.

17. Wang, C. Y.; Zhao, T. Chin. Chem. Lett. 2001, 12, 935.

18. Shen, S. B.; Ishida, H. J. Mater. Sci. 1996, 31, 5945.

19. Allen, D. J.; Ishida, H. J. Appl. Polym. Sci. 2006, 101, 2798.

20. Chernykh, A.; Agag, T.; Ishida, H. Polymer 2009, 50, 3153.

21. Chernykh, A.; Agag, T.; Ishida, H. Macromolecules 2009, 42, 5121.

22. Velez-Herrera, P.; Ishida, H. J. Polym. Sci. Part A: Polym. Chem. 2009, 47, 5871. 